\title{
Significado de la Virginidad y sus Implicancias Sociales en la Universidad Nacional Jorge Basadre Grohmann de Tacna 2010
}

\author{
Meaning of Virginity and its Social Implications in National \\ University Jorge Basadre Grohmann. Tacna 2010
}

\author{
${ }^{1}$ Carmen Linares Torres, ${ }^{2}$ Gema Sologuren Garcia
}

\begin{abstract}
RESUMEN:
El objetivo es analizar los significados que dan los estudiantes a la virginidad y las implicancias en sus interacciones sociales. Es una investigación cualitativa donde la muestra fue de 20 estudiantes de la UNJBG. Se utilizó las entrevistas en profundidad y grupo focal. Los resultados fueron: a) El concepto de virginidad se aprende en la vida social; b) En la familia se empieza a socializar este concepto; c) Persiste la idea que la virginidad es símbolo de honra, dignidad y respeto: d) La mayoria de los estudiantes tienen la idea que conservar la virginidad es una fortaleza; e) La enseñanza del valor de la conservación de la virginidad se da en un contexto de conflictos interculturales generacionales; f) Los estudiantes consideran la necesidad de valorar menos el concepto de virginidad; g) En los estudiantes aún no se ha generado rechazo ante el estereotipo de género de la virginidad.
\end{abstract}

Palabras claves: sexualidad, virginidad, implicancias sociales.

\section{ABSTRACT:}

The objective is to analyze the meanings that students give to about virginity and its implications to their social interactions. It is a qualitative research where the sample consisted of 20 UNJBG students. We used in-depth interviews and focus groups. The results were: a) The concept of virginity is learned in social life; b) This concept begins to be socialized in the family: c) There remains the idea that virginity is a symbol of honor, dignity and respect; d) The majority of students have the idea to preserve virginity as fortress; e) the teaching of the conservation of virginity as a value takes place in a context of generational inter cultural conflicts; f) Students consider the need to mis value the concept of virginity; g) It hasn't yet been generated rejection of the gender stereotype of virginity by student.

Keywords: sexuality, virginity, social implications.

\footnotetext{
' Magister en Docencia Universitaria. Licenciada en Obstetricia. Facultad de Ciencias de la Salud. Universidad Nacional Jorge Basadre Grolımann zMagister en Docencia Universitaria, Licenciada en Obstetricia. Facultad de Ciencias de la Salud. Universidad Nacional Jorge Basadre Grolimann
} 


\section{INTRODUCCIÓN}

La sexualidad humana se construye con una perspectiva social y de género, cuyos paradigmas la definen como algo intrínseco asociada a la perspectiva de género (Foucault, 1998). En este proceso de vivencia de nuestra sexualidad, está involucrado el constructo social "Virginidad". Se habla de la virginidad en voz baja, to hacen hombres y mujeres; pero son las mujeres las que deben asumir la carga de este estereotipo de género. En este sentido, la vivencia de la dimensión sexual está condicionada por el control social, a partir de un conjunto de reglas y normas sociales cuyo fundamento está en gran medida en la religión. En nuestro pais, la religión católica históricamente, ha representado y representa una gran fuerza, y para ella el valor de la virginidad está asociado con la culpa y el pecado. Pero, ¿si la mujer pierde el himen por un accidente? ¿si una chica nace sin himen?, ¿si perdió el himen por una violación sexual? Estas reflexiones no se hacen en una sociedad en la que existe desigualdad de género, y el resultado de ello es el control de la sexualidad femenina porparte del hombre.

Esta investigación se centra en analizar los significados que dan los y las estudiantes universitarios a la virginidad y las implicancias que estos significados tienen en sus interacciones sociales. A través de entrevistas en profundidad y grupo focal, se descubren los significados que los jovenes universitarios dan a la virginidad.

\section{MATERIALESY MÉTODOS}

Se tratará de una investigación de tipo cualitativa. El universo estuvo constituido por 6030 estudiantes matriculados en el año académico 2010 de la Universidad Nacional Jorge Basadre Grohmann de Tacna. La muestra estuvo formada por 20 estudiantes. Se utilizó la entrevista a profundidad haciendo uso de una guía semiestructurada ( 4 entrevistas con hombres y 4 entrevistas para mujeres) y grupo focal.

\section{RESULTADOSY DISCUSIÓN}

La definición de virginidad que los jóvenes universitarios tienen está basada en la concepción de la sexualidad que la sociedad les impone y la sociedad tiene interés en el cuidado de la pureza de la mujer. Por ello, cuando se les pregunta a los y las jóvenes sobre ¿qué es la virginidad?, sin excepción, todos hacen referencia a la presencia del himen y con ello podemos concluir básicamente en tres ideas: para ellos, la virginidad está reservada a la mujer; el concepto de virginidad que manejan es aprendido como un conocimiento único y final; para ellos existen dos tipos de mujeres, las que son virgenes y las que no lo son. Tambièn, está claro que la virginidad para los varones no es enseñada en la sociedad si no al contrario:

“... en la misma sociedad... decirle al hombre que es virgen es mal visto es un poco feminizado... si lo colocamos en un contexto religioso virgen se le ha colocado solo a la mujer, no se le a colocado al hombre". Juan.
Encontramos que las jóvenes universitarias cuidan su virginidad no para ellas, sino para los hombres y en esta situación no viven su sexualidad de manera libre y sana. El derecho a disfrutar su sexualidad es opacado por el "deber" que tienen de presentarse hacia el sexo opuesto como mujeres castas que asumirán, probablemente, de manera pasiva, la posición de una esposa que cumpla principalmente su rol reproductor. Se les ha enseñado a las mujeres que la virginidad es un tesoro que deben regalar al hombre para que las ame y las respete:

$" \ldots$ al entregar la virginidad demuestras tu gran amor hacia la otra persona...". Milagros.

No ser virgen es considerado por las mismas mujeres, un error:

"... yo no soy virgen pero... yo siempre digo que quiero que mi hermana... que su primera vez... a quién le va a entregar su virginidad... que sea con una persona con la que ella va a estar siempre". Libly

Asimismo, se puede observar una tendencia a resistirse a aceptar el concepto de virginidad, sin embargo no tienen suficientes argumentos para afrontar este constructo social. Esto se debe a que los significados que tienen de virginidad tienen fuertes componentes psicológicos y sociológicos. Hablamos de siglos de enseñanza de este estereotipo, y de pocos esfuerzos por educar sexualmente a nuestra población de parte del Estado:

"Sí es un concepto machista... el hombre es machista sigue siendo machista y seguira siendo machista". Oscar.

El método de enseñanza de la virginidad es principalmente el temor. El temor a la desvalorización como mujer:

"mi madre... que si yo no llegaba virgen al matrimonio, que mi esposo me podría maltratar, me podria discriminar me podria agredir". Angi.

El lenguaje usado para hablar de la virginidad, de parte de la madre suele ser subrepticio, como si algo impidiera el hablar del tema abiertamente con la hija.

"Escuchaba que a mi prima le decía su mamá: ¡tú tienes que cuidar bien tu florcita, ...tienes que cuidarla bien de acá pa' arriba no ma'!". Óscar.

En este punto Valdez, señala que el prohibir a las mujeres y a los hombres adolescentes iniciarse sexualmente es totalmente inadecuado. Lo adecuado es enseñar a los y las adolescentes que para tener relaciones sexuales no se está preparado desde la primera menstruación o primera eyaculación. Los seres humanos tienen otras dimensiones además de la biológica: la cultural y emocional.

La familia y los amigos son los espacios en los que los jóvenes universitarios socializaron los significados de virginidad. El tema es tratado como un tabú. El tema no se discute si no que se considera que es un axioma que 
hay que transmitir. Que su aprendizaje no requiere de reflexiones que demuestren su verdad. Tanto la familia como los amigos están de acuerdo con que la virginidad es igual a buen matrimonio para las mujeres, es igual a la valoración de las mujeres de parte de sus esposos. Aparentemente para la familia y los amigos, la virginidad sólo está directamente relacionada con la desfloración, en lo que se puede notar cierto grado de doble discurso, en este sentido tener sexo anal y sexo oral, probablemente no es sinónimo de ser virgen.

Los amigos y parientes de los hombres se convierten en un grupo de presión que aprueba o desaprueba la relación amorosa de un hombre adolescente en funcion de si la mujer es virgen o no. También presionan para la iniciación sexual durante la adolescencia.

"Tenia mi grupo de anigos, hasta ahora si he escuchado to de las Cucardas. (es un prostibulo) hasta hoy en dia no tuve la oportunidad...". Oscar

Segun Valdez. los padres no pueden imponer una edad especifica para el inicio sexual a sus hijos. Es una decision personal y el mejor consejo de los progenitores está en el ejemplo y conversar sobre la práctica del sexo seguro.

Es interesante el hecho que los jóvenes universitarios puedan conversar sobre el tema de la virginidad en grupos de ambos sexos. En un espacio de esta naturaleza se ponen en cuestión las caracteristicas del constructo social virginidad. En este espacio se confrontan posiciones sexistas y se reformulan conceptos con un carácter más democrático.

"Una vez conversando con mis amigas llegamos a ese punto, conversamos que siempre o la mayoria de los casos el hombre planea la primera vez y yo les di la razón. generalmente siempre es así por eso que dicen que todos los hombres son iguales yo me puse a pensar...". Oscar.

Algunos padres de adolescentes presionan a los hijos hombres para perder la virginidad. Las madres no aparecen en la socialización de los significados de virginidad de los hijos varones para ensenarles que deben cuidar su virginidad como sí lo hacen con las hijas mujeres. En algún caso de madre sola con experiencias negativas con su pareja suele aconsejarle sobre el respeto hacia las mujeres pero no para aconsejarle que conserve su virginidad.

-Porque mi mamá me decía que hombre no es aquel que se acuesta con muchas mujeres, hombre es aquel que sabe respetary valorar a una mujer..." Juan.

Amuchástcgui. en un trabajo de significado de la virginidad y la iniciación sexual afirma que aunque los mandatos acerca de a virginidad de las mujeres y de la primera relación sexual de los hombres están muy presentes en los relatos, también lo están innumerables acciones $y$ construcciones de resistencia y desobediencia. Sin embargo, la relación entre estos discursos dominantes y subyugados no parece ser de oposición o lucha frontal, sino de ambigüedad y tolerancia. Es decir, estos discursos parecen coexistir sin chocar realmente o elim inarse mutuamente. Si este fuera el caso, las transgresiones al mandato de preservar la virginidad para las mujeres tendrian que haber sido castigado, por ejemplo, con el rechazo por parte de los esposos. Sin embargo. lo que parece haber sucedido es que los discursos morales no se encuentran con los de la práctica, de modo que lo que se dice en un nivel no se opone realmente al otro.

Entre las jovenes universitarias que participaron de la presente investigación, sólo una de ellas se animó a decir que no era virgen, la mayoria de las jóvenes dijo que era positivo que las mujeres se conservaran virgenes hasta el matrimonio pero no afirmaron que ellas lo eran.

En el grupo focal. la mayoria de los varones se expresó sobre el tema de no ser virgenes con mucha soltura, $y$ varios de ellos alirmaron directamente que no eran virgenes. Probablemente las mujeres no vírgenes se vieron "obligadas" a no admitir que no eran virgenes. por la presencia de hombres que podrian juzgarlas por este hecho. Este hallazgo coincide con lo manifestado por Amuchástegui, las jóvenes solteras hablan de la importancia de la virginidad pero no la preservan y los hombres afirman con firmeza el derecho del novio a rechazar a una novia que no sea virgen, mientras que la mayoria aceptaron a sus compañeras a pesar de no ser virgenes.

\section{CONCLUSIONES}

1. La virginidad es un constructo social porque es producto de una socialización primaria y secundaria, en la sociedad. Siendo la familia el primer lugar de la interacción social del individuo. es alli donde se empieza a socializar el concepto de virginidad. Otros espacios en donde más adelante se sigue construyendo el concepto de virginidad, son los amigos, los compañeros de la escuela. la escuela como institución, principalmente. El concepto de virginidad se aprende como cualquier otra conducta. en la vida social, con modelos y ejemplos de los pares y de los adultos.

2. El tabu de la virginidad no ha desaparecido por completo de la vida de los y las estudiantes. Está presente en sus imaginarios con un sello de estereotipo de género. Persiste la idea, que la virginidad es un simbolo de honra. dignidad y respeto para las mujeres, sin embargo, consideran que su conservación es parte de las presiones de la adolescencia que claramente son muestras de que vivimos en una sociedad machista. Cabe señalar, que en los conceptos de los y las estudiantes universitarias no se encuentran expresiones con componentes religiosos o morales.

3. La mayoria de las y los estudiantes tienen aprendida la idea de que conscrvar la virginidad para la mujer es una fortaleza de las mujeres que les darán en el futuro la posibilidad de ser apta para el matrimonio. generándose asi un acto de discriminación contra 
muchas mujeres.

4. Son las madres las cuidadoras de la virginidad de las hijas, más no de los hijos hombres. El proceso de ensenanza del valor de la conservación de la virginidad de madre a hija se da en contexto de conflictos interculturales generacionales, pero sobre la inica base del valor moral que para estas madres represento conservar su virginidad. FI mensaje de la madre a la hija es bastante simple: la mujer debe esperar que los hombres la vean y la reconozan como una mujer digna de ser su companera ante la sociedad.

5. A traves del estereotipo de género de la virginidad. la sociedad impide el libre ejercicio de la sexualidad y afecta la intmidad no solo de las mujeres sino tambien de los hombres, pues al imponer la idea de que la mujer que vale es la mujer virgen. les niega a ambos sexos amar con libertad y dentro de sus propias ideologias de vida. Reduce el concepto del amor al cucrpo y les niega la posibilidad de vivir el amor de manera integral

6. Los jovenes y las jovenes consideran que en la actualidad hat ana necesidad de salorar menos o al menos de manera diferente. of concepto de virginidad de las mujeres. Se trata de concebir la "pértida de la virginidad" simplemente como el intero de la sexualidad. tanto de hombres como de meletes. Sin empargo entre los participantes de esta incestigatom no se ha genefado an el rechazo contumente ante el esterentipo de genero rirginidad.

\section{REIERENCIAS BIBLIOGRAFICAS}

Alcantara, J. "I a virginidad": un aprendizaje cultural: 2010

Amuchastegui A. H significado de la virginidad y la iniciacion sexual. In relato de investigación. En: Szasz. O. Lerner S, compiladoras. Para comprender la subjetividad. Investigacion cualitativa en salud reproductiva y sexualidad. Mexico: El Colegio de México:1999

Diaz E. Los contextos sociales en el proceso de construceion de la sexualidad del joven. BelloAntioquia. Universidad de Antioquia: 2008

Fernande\% A. Estereotipos de Género en el refranero popular "De la mujer mala te has de guardar y de la mujer buena no fiar". Universidad Autonoma Metropolitana Xochimilco; 1996
Flores S. Jóvenes universitarias que legitiman la violencia en sus relaciones de pololeo. Tesis para optar al Titulo de Asistente Social. Licenciado en Desarrollo Familiary Social. Temuco: 2004.

Lundgren. R. Protocolos de investigación para el estudio de la salud sexual y reproductiva de los adolescentes varones y hombres jóvenes en America Latina. División de Promoción y Protección de la Salud Programa de Familia y Poblacion. OPS; 2000

Manzelli. Hernán. Centro de Estudios de Población CENEP Universidad de Buenos Aires.

Socorro M. Procesos de afïrmación y de construcción de los mitos sobre el cuerpo femenino: continuidad y ruptura de los modelos patriarcales del mundo antiguoy contempotáneo: 2000 .

Vargas. G. Representación social de la virginidad en México. Planiel "Ignacio Ramirez Calzada”. de la Fscuela Preparatoria. UAFM: 2008

\section{WFB}

Amuchástegui. Ana. Virginidad. La doble moral en la formacion de las y los jovenes. [en línea] [accesado 12 mayo 20101 . Disponible en

http: whw.letraese org. $m x$ virginidad.htm

Foucault. M. Historia de la sexualidad. El uso de los placeres. [en linea] [accesado 18 may 20101. Disponible hup: es.scribulcom doc 6847411 Foucault-MichelIlistoria-de-fa-sevalidad-II-El-aso-de-los-placeres

Ortega R. II concepto de la virginidad muchas veces es confundido con el de la abstinencia. [en linea] [accesado 02 abr 20101 . Disponible en

http: www.puntovital.cl/seso/sano/virginidad.htm

Valdez M. Desfloracion. la entrada a la sexualidad. [en linea] [accesade 30 jun 2010]. Disponible en htup: www tuaporte.com/forosmf/salud-y-bienestar.

\section{Correspondencia:}

Carmen Linares Torres

Ciudad Universitaria Fundo "Los Granados"

Av. Miratlores s n. Tacna. Perú

Villa Las Flores F-14 Pocollay. Tacna. Perú

clinares40 ähotmail.com 